\title{
Urethrovaginal fistulae associated with tension-free vaginal tape procedures: a clinical challenge
}

\author{
Christl Reisenauer • Julian Janowitz • \\ Diethelm Wallwiener • Markus Huebner
}

Received: 5 July 2013 / Accepted: 10 August 2013 / Published online: 13 September 2013

(C) The International Urogynecological Association 2013

\begin{abstract}
Seven women with urethrovaginal fistulae and penetration of tension-free vaginal tape into the urethra were treated at our department between July 2007 and March 2013. Fistulae were diagnosed 1 month to 10 years after midurethral sling placement. All were managed surgically. Five patients developed recurrent postoperative stress urinary incontinence, which was treated conservatively in all cases. In three cases, additional surgical treatment using a midurethral sling was performed.
\end{abstract}

Keywords Tension-free vaginal tape $\cdot$ Midurethral sling ·

Stress urinary incontinence $\cdot$ Urethrovaginal fistula

\section{Introduction}

The tension-free vaginal tape procedure is an effective treatment for stress urinary incontinence (SUI). Despite the minimally invasive nature of this procedure, serious complications, such as urethrovaginal fistulae, can occur. Urethra reconstruction can be a challenge for the surgeon. In addition, SUI may occur subsequent to tape removal and fistula repair, thus aggravating the situation. We report the surgical repair of seven urethrovaginal fistulae that occurred after tension-free vaginal tape procedures and subsequent treatment of SUI.

\section{Material and methods}

Seven women with urethrovaginal fistulae and penetration of the tension-free vaginal tape into the urethra were referred to our department between July 2007 and March 2013.

C. Reisenauer $(\bowtie) \cdot \mathrm{J}$. Janowitz $\cdot$ D. Wallwiener $\cdot$ M. Huebner Department of Obstetrics and Gynecology, University Hospital Tübingen, Calwerstrasse 7, 72076 Tübingen, Germany

e-mail: christl.reisenauer@med.uni-tuebingen.de
Patient characteristics are summarized in Table 1. Five patients had undergone a sling procedure with retropubic TVT ${ }^{\mathrm{TM}}$ (Gynecare Ethicon Inc, Somerville, NJ, USA), one with transobturator outside-in Monarc ${ }^{\mathrm{TM}}$ Sling (AMS, Minnetonka, MN, USA), and one with transobturator inside-out TVT-O $^{\text {TM }}$ (Gynecare Ethicon).

Four of seven women had already had partial tape removal and urethrovaginal fistula closure at another hospital. Those four women were referred to our department with a recurrent urethrovaginal fistula.

\section{Results}

All seven patients complained about urethral pain, repeated urinary infections, and urine loss. Vaginal examinations revealed urethrovaginal fistulae (Figs. 1b and 2b). Urethroscopy showed size and localization of the urethrovaginal fistulae (Fig. 1a) and the tape in cases in which it had not previously been removed (Fig. 2b).

All patients were operated by the first author. In two of seven patients, the suburethral part of the tape was excised and the urethral defect closed with 3-0 interrupted polyglactin sutures in two tension-free layers. Recurrent urethrovaginal fistulae were closed using a Martius flap in three cases and a vaginal flap in one. We chose the vaginal flap to repair the fistula situated close to the external urethral meatus. Postoperatively, the patients had suprapubic urine drainage for 3 weeks. The indwelling urethral catheter was removed on the third postoperative day. We decided to treat one patient with ileal conduit due to her completely destroyed urethra associated with severe incontinence. Wound healing was uneventful in all cases.

After fistula closure, five of the seven patients complained about SUI. The patient with the vaginal flap repair and the one with the ileal conduit were continent. SUI was treated conservatively in all cases. In three cases, additional surgical treatment 
Table 1 Characteristics of patients with urethrovaginal fistulae

\begin{tabular}{|c|c|c|c|c|c|}
\hline $\begin{array}{l}\text { Case } \\
\text { number }\end{array}$ & $\begin{array}{l}\text { Age at fistula } \\
\text { diagnosis }\end{array}$ & $\begin{array}{l}\text { Tape } \\
\text { placement }\end{array}$ & $\begin{array}{l}\text { Fistula diagnosis and } \\
\text { treatment at other } \\
\text { hospitals }\end{array}$ & $\begin{array}{l}\text { Fistula treatment at our } \\
\text { department }\end{array}$ & $\begin{array}{l}\text { Final stress urinary } \\
\text { incontinence treatment at } \\
\text { our department }\end{array}$ \\
\hline 1 & 45 & 5/2006 Monarc & $7 / 2007$ & $\begin{array}{l}\text { 7/2007 partial suburethral Monarc } \\
\text { sling removal and two-layer closure }\end{array}$ & $\begin{array}{l}\text { 6/2008 TVTTM after ineffective } \\
\text { conservative treatment }\end{array}$ \\
\hline 2 & 55 & 2007 TVT $^{\mathrm{TM}}$ & $3 / 2013$ & $\begin{array}{l}\text { 3/2013 partial suburethral TVTтм } \\
\text { removal and two-layer closure }\end{array}$ & Conservative treatment ongoing \\
\hline 3 & 67 & 2/2012 TVT Тм & $\begin{array}{l}5 / 2012 \text { partial TVTTM removal } \\
\text { and closure of urethral wall }\end{array}$ & Recurrent fistula $11 / 2012$ Martius flap & $\begin{array}{l}\text { 4/2013 TVT }{ }^{\mathrm{TM}} \text { after ineffective } \\
\text { conservative treatment }\end{array}$ \\
\hline 4 & 40 & 9/2009 TVT-O & $\begin{array}{l}\text { 9/2009 partial TVT-O } \\
\text { removal and closure of } \\
\text { urethral wall }\end{array}$ & Recurrent fistula 10/2009 Martius flap & $\begin{array}{l}\text { 12/2010 TVTTM after ineffective } \\
\text { conservative treatment }\end{array}$ \\
\hline 5 & 44 & 3/2012 TVT Tм & $\begin{array}{l}\text { 10/2012 partial TVT }{ }^{\mathrm{TM}} \text { removal } \\
\text { and closure of urethral wall }\end{array}$ & Recurrent fistula 3/2013 Martius flap & Conservative treatment ongoing \\
\hline 6 & 47 & 2004 TVTTM $^{\text {тм }}$ & $\begin{array}{l}2009 \text { partial TVT }{ }^{\mathrm{TM}} \text { removal } \\
\text { and closure of urethral wall }\end{array}$ & Recurrent fistula 9/2011 Vaginal flap & No stress urinary incontinence \\
\hline 7 & 80 & $2000 \mathrm{TVT}^{\mathrm{TM}}$ & 1/2010 partial TVT Tм removal & $\begin{array}{l}6 / 2010 \text { complete } \text { TVT }^{\mathrm{TM}} \text { sling } \\
\text { removal due to persistent extensive } \\
\text { inflammation of the anterior } \\
\text { vaginal wall reaching high } \\
\text { into the retropubic space }\end{array}$ & 2/2012 ileal conduit \\
\hline
\end{tabular}

was performed. Due to lack of urethral mobility and intrinsic urethral deficiency, patients were operated using a retropubic tension-free vaginal tape (Gynecare Ethicon). These patients were subjectively and objectively cured. Two patients were receiving conservative treatment when this report was written.

\section{Surgical management}

Atrophic vaginitis was treated with topical estrogens prior to surgical repair. A Foley catheter was placed into the bladder. A circumferential incision was made around the fistula, and the urethral and vaginal walls were mobilized and separated. Extensive mobilization of the periurethral tissue is necessary to ensure a tension-free closure. Extensive excision of perifistular tissues was avoided to prevent an iatrogenic increase in fistula diameter. Interrupted 3-0 polyglactin sutures were placed transversally through the urethral wall to minimize urethral narrowing. The second suture line was placed without tension, using periurethral and perivaginal tissue, thus creating a layer between urethra and vagina. The Foley catheter was left in the bladder for 3 days, and the suprapubic catheter was left in place for 3 weeks to provide continuous drainage. Recurrent urethrovaginal fistulae were closed using either a vaginal or a Martius flap. The vaginal flap technique was performed as described by Reisenauer et al. [1]. In the cases in which the Martius flap was used, the urethral suture line was reinforced by interposing a mobilized, wellvascularized fat pad from the labia majora. The fat pad was tunneled beneath the labia minora into the vaginal lumen, where it was sutured to the urethral wall.
Fig. 1 Urethroscopy shows the size and location of a recurrent urethrovaginal fistula after partial removal of the tension-free tape (a). Vaginal examination reveals the urethrovaginal fistula (b)
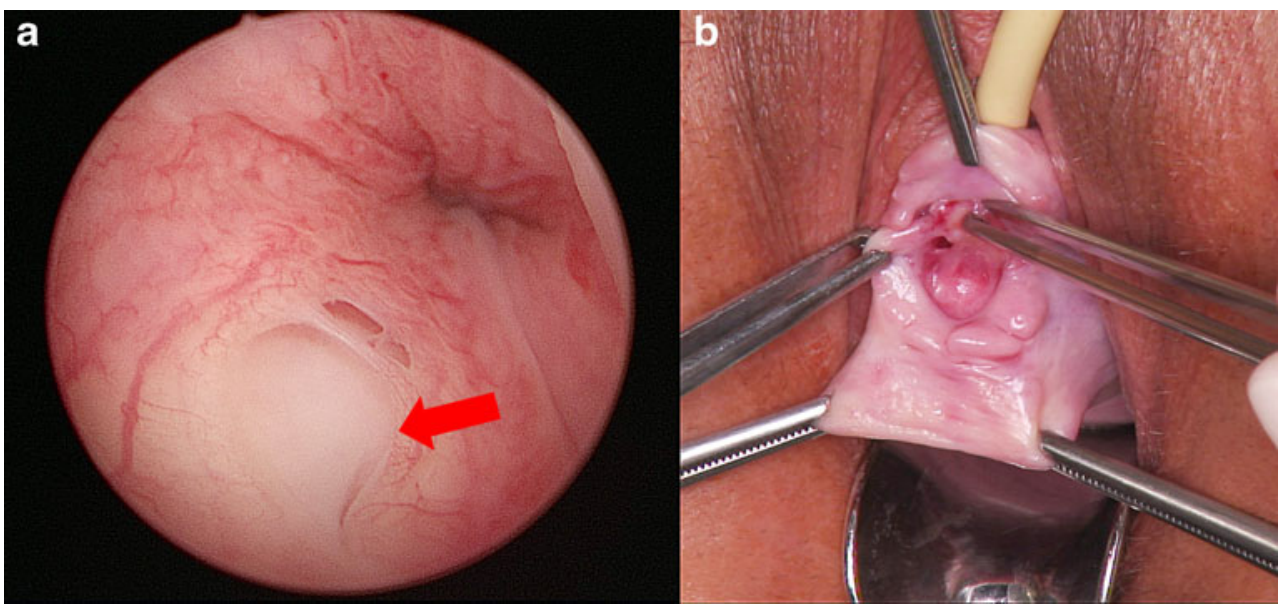
Fig. 2 Urethroscopy shows erosion of the tension-free vaginal tape into the urethra (a). Vaginal examination reveals the urethrovaginal fistula (b)

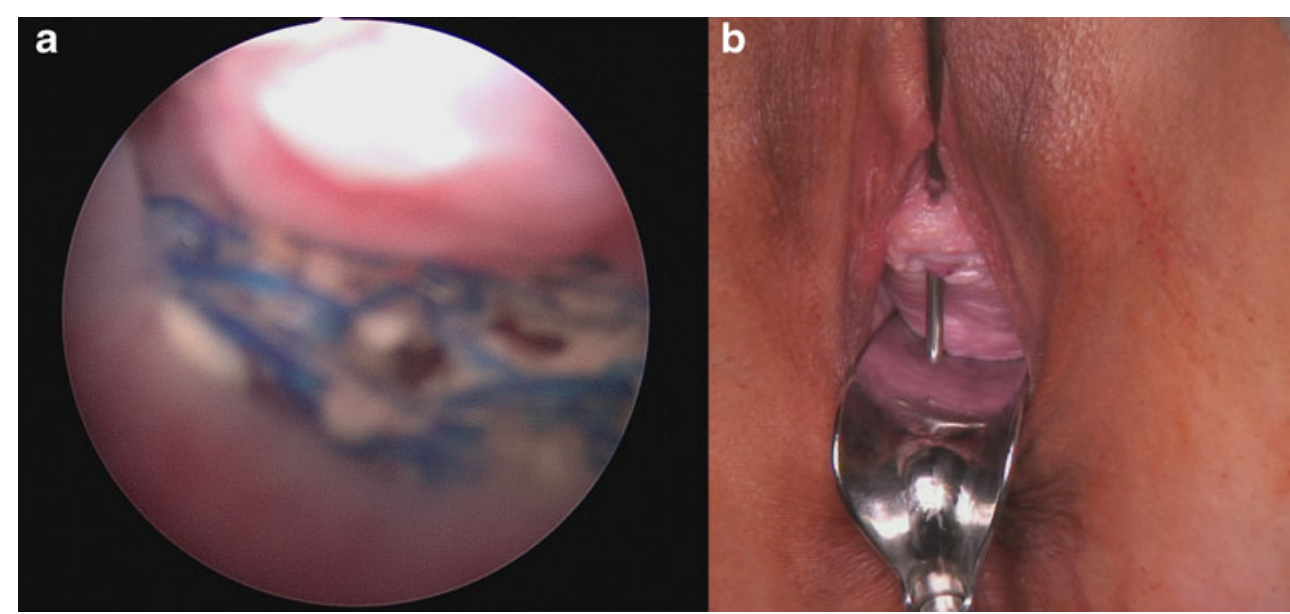

\section{Discussion}

Midurethral slings with a low rate of major complications have become one of the most common procedures for treating SUI. Urethrovaginal fistula is a rare but severe complication after tension-free vaginal tape placement. We present the management of urethrovaginal fistulae diagnosed 1-14 months and 510 years after midurethral sling placement. The exact etiology of these urethrovaginal fistulae is not known. Fistulae occurring shortly after sling placement may be due to urethral injury during the surgery itself or following urethral dilatation to treat postoperative voiding difficulties [2]. Fistulae diagnosed years after the tape procedure may be explained by sling penetration into the urethra over the years.

In our study, five of seven women complained about persistent SUI after urethrovaginal fistula repair. After fistulae closure, we placed retropubic tension-free vaginal tapes (TVT ${ }^{\mathrm{TM}}$ ) in three women, as conservative treatment of persistent SUI proved ineffective.

Concomitant fistula closure and synthetic midurethral sling placement in patients with concurrent urethrovaginal fistula and SUI may increase the risk of adverse events. Appropriate management of concomitant urethrovaginal fistula and SUI is widely debated. There are no comparative trials supporting staged or concomitant surgery. Smith et al. report a surgical technique in which interposition of a biological graft between a repaired urethrovaginal fistula and a tension-free synthetic sling was performed. The fistula occurred following a urethral diverticulectomy [3]. Carey et al. performed the incontinence procedure at the same time as fistula repair using an autologous pubovaginal sling [4]. Estevez et al. report a case of urethrovaginal fistula occurrence 39 months after TVTTM (Ethicon Gynecare) placement. They removed the tape and closed the urethra defect with transversally placed uninterrupted absorbable monofilament suture. Paraurethral tissues were closed, creating an intermediate layer between urethra and vagina using interrupted absorbable monofilament sutures. Eleven months after successful fistula closure, the patient was continent [5]. Siegel reports about a 64-year-old woman with SUI who underwent TVT $^{\mathrm{TM}}$ placement that resulted in a large fistula between the proximal urethra and the vagina, leading to necrosis of the urethra distal to the fistula. Reconstruction was done in three stages: initially, the patient underwent debridement and removal of the TVT fragments. Then vaginal-flap urethroplasty with a labial fibrofatty graft was performed to restore urethral length. Finally, a coaptive occlusive sling was placed to restore continence [6].

Advantages and potential risk of the surgery should be discussed with the patient, and treatment should be individualized, taking into account fistula etiology. Primary fistulae can be closed using multilayer closure. Recurrent fistulae should be closed by using a graft interposition. We used the Martius flap for the midurethral fistula and a vaginal flap for the fistula situated close to the external urethral meatus, as the latter can be reconstructed with the flap as well. Golomb et al. [7] present a technique of recurrent urethrovaginal fistula repair combined with SUI treatment using a fascial patch graft and at the same time placing a pubovaginal sling. The recurrent fistula occurred after removal of an eroded TVT and repair with a Martius flap. The fistula healed, and the patient regained continence. Other flaps described in literature for successfully reconstructing urethrovaginal fistulae are full-thickness free graft of labium minus [8], pedicled rectus abdominis muscle flap [9], and gracilis muscle interposition [10]. These procedures are associated with a greater morbidity rate than the Martius flap technique.

The cases reported here should raise awareness of potential complications that can occur after midurethral sling placement. During the synthetic tape placement, care must be taken to avoid urethral trauma. To reduce morbidity, each case should be considered individually. 
Financial disclaimer/ conflict of interest statement Christl Reisenauer: acceptance of paid travel expenses or honoraria (such as Speaker's Bureau) Ethicon Gynecare, Astellas and acceptance of payment for research Ethicon Gynecare

Julian Janowitz, Diethelm Wallwiener, and Markus Huebner: none

\section{References}

1. Reisenauer C, Wallwiener D, Stenzl A, Solomayer FE, Sievert KD (2007) Urethrovaginal fistula-a rare complication after the placement of a suburethral sling (IVS). Int Urogynecol J 18:343346

2. Vassallo BJ, Kleeman SD, Segal J, Karram MM (2003) Urethral erosion of a tension-free vaginal tape. Obstet Gynecol 101:10551058

3. Smith AL (2013) Biologic grafted repair of urethrovaginal fistula and concomitant synthetic sling. Int Urogynecol J 24:729-730. doi:10. 1007/s00192-012-1996-4
4. Carey MP, Goh JT, Fynes MM, Murray CJ (2002) Stress urinary incontinence after delayed primary closure of genitourinary fistula: a technique for surgical management. Am J Obstet Gynecol 186:948-953

5. Estevez JP, Cosson M, Boukerrou M (2010) An uncommon case of urethrovaginal fistula resulting from tension-free vaginal tape. Int Urogynecol J 21:889-891. doi:10.1007/s00192-009-1067-7

6. Siegel AL (2006) Urethral necrosis and proximal urethro-vaginal fistula resulting from tension-free vaginal tape. Int Urogynecol J 17:661-664

7. Golomb J, Leibovitch I, Mor Y, Nadu A, Ramon J (2006) Fascial patch technique for repair of complicated urethrovaginal fistula. Urology 68:1115-1118

8. McKinney DE (1979) Use of full thickness patch graft in urethrovaginal fistula. J Urol 122:416

9. Bruce RG, El-Galley RE, Galloway NT (2000) Use of rectus abdominis muscle flap for the treatment of complex and refractory urethrovaginal fistulas. J Urol 163:1212-1215

10. Patil U, Waterhouse K, Laungani G (1980) Management of 18 difficult vesico-vaginal and urethra-vaginal fistulas with modified Ingelman-Sundeberg and Martius operations. J Urol 123: 653-656 